\section{Oxygen Content and its Diurnal Variation in a New Recirculanting Water Soilless Culture for Horticultural Crops}

\author{
Miguel Urrestarazu, ${ }^{1}$ Pilar Carolina Mazuela, ${ }^{2}$ Abdelaziz Boukhalfa, \\ Antonia Arán, ${ }^{3}$ and María del Carmen Salas ${ }^{1}$ \\ Departamento de Producción Vegetal, Universidad de Almería, E-04120 \\ Almería, Spain \\ Additional index words. soilless culture, water culture system, root oxygen, tomato, cucumber, \\ sweet pepper
}

Abstract. Based on a new structure for plastic culture channels, a new system for soilless culture called New Growing Systems (NGS) has been developed. It is similar to the nutrient film technique (NFT) but with several potential advantages. Each NGS growing channel has five plastic layers and a large number of holes, there is a dripper every $0.5 \mathrm{~m}$ above the first layer of plastic, and each dripper supplies the nutrient solution which flows from the second layer over the others to the end. Three separate greenhouse experiments with tomato, cucumber, and sweet pepper using NGS channels were conducted in Almería (southeastern Spain). The oxygen content in the circulating nutrient solutions was determined at different points and different times along the channels of all crops. Depletion of oxygen content in the nutrient solution was lower than NFT channels. Oxygen content in NGS showed some advantages compared to NFT.

Roots have to find oxygen in their immediate environment (Drew, 1983). Early studies about oxygen content in nutrient solution have shown that inadequate aeration may cause waterlogging in the roots of many plants; and that sufficient forced aeration may be very expensive (Zeroni et al., 1983). It is known that oxygen concentration in the nutrient solution of an important number of experiments is a limiting factor for plant growth (Adams, 2002; Morard et al., 2000; Zeroni et al., 1983). Gislerød and Kempton (1983) described variations in oxygen content of the nutrient film technique (NFT) solution during the daytime growth of cucumbers and tomatoes.

Nutrient-film technique crop production is a growing method, in which the plants have their roots in a shallow stream of recirculanting nutrient solution. This growing system can be found all around the world and has been in use commercially since the 1970s (Carrasco, 2004; Cooper, 1996).

Based on a new structure for plastic culture channels, a private company invented and has been developing a new system in soilless culture over the last few years, it is called New Growing Systems (NGS) and is similar to NFT but with several potential advantages.

Since the 1990s NGS have been improved with commercial successful, between Spain, Italy and Mexico, the total commercial area using the NGS today is estimated to be about 100 ha.

The present experiments studied the oxygen content of the new NGS. This was analyzed under commercial conditions and compared with the traditional NFT.

Received for publication 1 May 2005. Accepted for publication 18 June 2005.

${ }^{1}$ Corresponding author; e-mail mgavilan@ual.es.

${ }^{2}$ Universidad de Tarapacá, Chile.

${ }^{3}$ Departamento Técnico, New Growing System, Spain.

\section{Materials and Methods}

Three separate greenhouse experiments were conducted with NGS channels in Alm- cucumber ('Cuzco') and sweet pepper ('Marumba') were propagated in rockwool cubes and placed in the channels in February, July, and August respectively. Plant density was one plant per square meter for cucumber and two for tomato and sweet pepper. The nutrient solutions were similar to that used by Sonneveld and Straver (1994). Before the nutrient solution was recycled, it was poured into the catchment tank. The volume of solution in the catchment tank was maintained, a nutrient solution of the same composition and $\mathrm{pH}$ as was added to the tank at the beginning of the day. Temperatures were between 12 and $22^{\circ} \mathrm{C}$.

The plastic channels were $22 \mathrm{~m}$ long and $2 \mathrm{~m}$ apart. The morphology, different layers and the holes between them of NGS channelare shown in Fig. 1. There was a slope $2 \%$, and a dripper every $0.5 \mathrm{~m}$ above the plastic channels. Each dripper supplied the nutrient solution which flowed from the second layer over the others to the end.

Each experiment was carried out in 2500 $\mathrm{m}^{2}$. One plastic channel was the experimental unit and this was chosen at radom inside of greenghouse. Oxygen in the circulating nutrient solutions was determined by a WTW Oxi 340 oximeter. Samples of the nutrient solution were collected at six different points in the three experimental units, three from the final drainage of different channels and the three drippers. The procedure use were according to (1983) using 2-mL glass svringes.

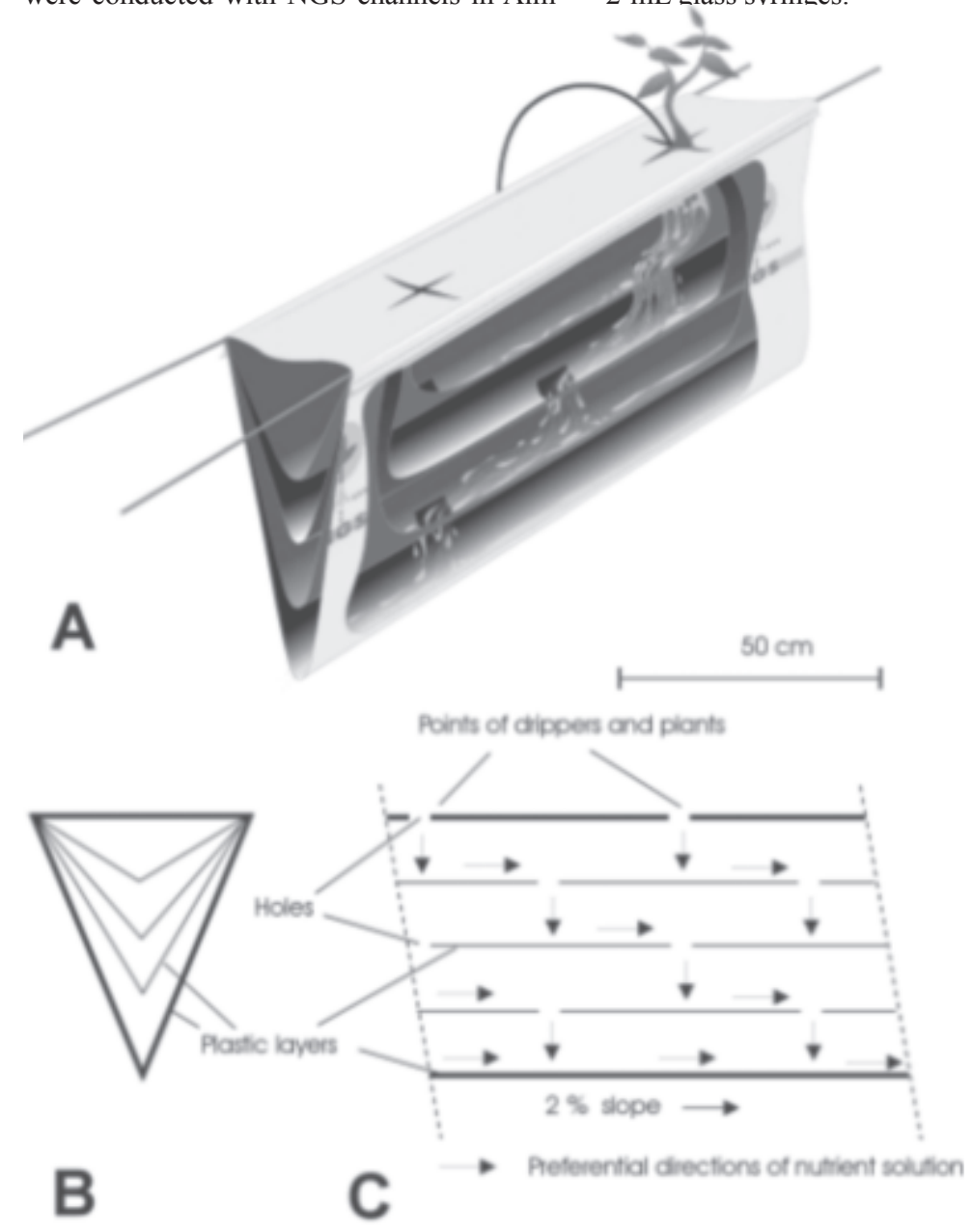

Fig. 1. General view (A), transversal (B), and longitudinal (C) section of a channel of the New Growing System (NGS) with five layers and their holes in the three inside one. 
The LSD test and single $t$ student probability were used to distinguish between the averages of the oxygen content hours, nutrient solution and drainage.

The Stagraphics Plus 4.1 statistical package was used to calculate data (Statistical Graphics Corp., 1999).

\section{Results and Discussion}

In the nutrient solution of all crops the oxygen content(Table 1) was higher than those values described as a limiting factor by Zeroni et al. (1983) in tomato (3 to $\left.4 \mathrm{mg} \cdot \mathrm{L}^{-1}\right)$, or that $\left(2.7 \mathrm{mg} \cdot \mathrm{L}^{-1}\right)$ observed in cucumber under NFT (Gislerød and Adams, 1983), and above $3 \mathrm{mg} \cdot \mathrm{L}^{-1}$ suggested as the limiting oxygen concentration in nutrient solution (Gislerød and Kempton, 1983).

Depletion of the solution oxygen content in the channels may be defined as the difference between the oxygen content in the catchment tank and fertigation drippers in comparison to the outlet end of channel drainage (Gislerød and Adams, 1983).

When studied the daily average in relation to oxygen content in solution supplied and drainage, a highly significant difference in the depletion of oxygen.

Data of oxygen content in the spring-summer tomato crop were lower than the autumn cycle was similar to cucumber and sweet pepper in the same cycle. To some extent, oxygen depletion in the channels, ease of gaseous exchange between the flowing solution and the atmosphere, the rate of exchange between the solution and the atmosphere are also affected by the thickness of the root mat (Gislerød and Adams, 1983). In these experiments, the root mat of cucumber was twice as thick as formed by tomato and sweet pepper, this also agrees with the report by Gislerød and Adams (1983) on tomato and sweet pepper, but the NGS depletion of the oxygen content was lower than NFT, this indicates a higher availability of oxygen to root mat. While growing cucumber in NFT, Gislerød and Kempton (1983) found a depletion from 6.2 to $2.9 \mathrm{mg} \cdot \mathrm{L}^{-1}(>50 \%)$ over a distance of $5 \mathrm{~m}$, this experiment in similar conditions using NGS recorded a decline from 7.12 to $6.65 \mathrm{mg} \cdot \mathrm{L}^{-1}$ (about $7 \%$ ) over a distance of $20 \mathrm{~m}$. This could be the main advantage of NGS in comparison to NFT, particularly because the length is very

Table 1. Diurnal variations of the oxygen content $\left(\mathrm{mg} \cdot \mathrm{L}^{-1}\right)$ in fertigation of a new water culture system [New Growing System $\left(\mathrm{NGS}^{\circledR}\right)$ ] during full production

\begin{tabular}{|c|c|c|c|c|}
\hline $\begin{array}{l}\text { Crop, } \\
\text { cycle, } \\
\text { month }\end{array}$ & $\begin{array}{l}\text { Time } \\
\text { (h) }\end{array}$ & $\begin{array}{l}\text { Nutrient } \\
\text { solution }\end{array}$ & Drainage & Significance \\
\hline \multicolumn{5}{|l|}{ Tomato } \\
\hline \multicolumn{5}{|l|}{ Spring-summer } \\
\hline \multirow[t]{3}{*}{ May } & 10 & 5.63 & 4.33 & $* * *$ \\
\hline & 12 & 4.70 & 4.47 & NS \\
\hline & 17 & 6.10 & 5.40 & NS \\
\hline $\mathrm{LSD}_{0.05}$ & & 1.24 & 0.42 & \\
\hline $\mathrm{LSD}_{0.01}$ & & --- & 0.64 & \\
\hline Day average & & 5.48 & 4.73 & $* *$ \\
\hline \multicolumn{5}{|l|}{ Fall-winter } \\
\hline \multirow{3}{*}{ September } & 10 & 9.60 & 7.83 & * \\
\hline & 12 & 8.67 & 7.37 & * \\
\hline & 17 & 9.13 & 7.67 & $* *$ \\
\hline $\mathrm{LSD}_{0.05}$ & & 0.64 & --- & \\
\hline $\mathrm{LSD}_{001}$ & & --- & --- & \\
\hline Day average & 9.13 & 7.62 & $* * *$ & \\
\hline \multirow{5}{*}{ November } & $9: 30$ & 9.33 & 7.46 & $* * *$ \\
\hline & $11: 30$ & 9.15 & 7.25 & $* *$ \\
\hline & $13: 30$ & 9.08 & 6.36 & $* * *$ \\
\hline & $15: 30$ & 7.72 & 5.01 & $* * *$ \\
\hline & $17: 30$ & 9.08 & 6.66 & $* * *$ \\
\hline $\mathrm{LSD}_{0.05}$ & & 0.20 & 0.47 & \\
\hline $\operatorname{LSD}_{0.01}^{0.00}$ & & 0.27 & 0.63 & \\
\hline Day average & & 8.92 & 6.63 & $* * *$ \\
\hline \multicolumn{5}{|l|}{ Cucumber } \\
\hline \multicolumn{5}{|l|}{ Fall-winter } \\
\hline \multirow{3}{*}{ September } & 10 & 7.60 & 7.00 & $* * *$ \\
\hline & 12 & 6.20 & 5.53 & $* * *$ \\
\hline & 17 & 7.57 & 7.13 & NS \\
\hline $\mathrm{LSD}_{0,05}$ & & 0.72 & 0.65 & \\
\hline $\mathrm{LSD}_{0.01}$ & & 1.10 & 0.98 & \\
\hline Day average & & 7.12 & 6.65 & * \\
\hline \multicolumn{5}{|l|}{ Pepper } \\
\hline \multirow{2}{*}{\multicolumn{5}{|c|}{$\begin{array}{l}\text { Fall-winter } \\
\text { October }\end{array}$}} \\
\hline October & & & & \\
\hline & $9: 30$ & 8.80 & 8.20 & $* * *$ \\
\hline & $11: 30$ & 8.47 & 8.27 & NS \\
\hline & $13: 30$ & 7.43 & 7.03 & $*$ \\
\hline & $15: 30$ & 7.83 & 7.33 & * \\
\hline & $17: 30$ & 8.43 & 8.03 & $*$ \\
\hline $\mathrm{LSD}_{0.05}$ & & 0.35 & 0.17 & \\
\hline $\mathrm{LSD}_{0.01}$ & & 0.50 & 0.24 & \\
\hline Day average & & 8.19 & 7.77 & $* * *$ \\
\hline
\end{tabular}

$\overline{\mathrm{NS}, *, * *, * * *}$ Nonsignificant or significant at $P \leq 0.05,0.01$, or 0.001 . The values are averages of three replications.

much a practical problem, in fact this is a limiting factor when NFT is used (Carrasco, 2004), but here there is no limiting factor even in these experiments when an NGS channel about four times longer than NFT was used.

The oxygen content of drippers and drainages declined significantly to a minimum during the brightest part of the day, or just before, in all crops; this was according to Jackson(1980)andGislerød and Adams (1983). However, if the depletion of oxygen content was compared as a percentage, significant differences between $2 \%$ and $35 \%$ were found, these variations were recorded at 11:30 HR during October with the pepper and at 15:30 HR during November in spring and summer tomato; in each crop the maximum oxygen absorption was around midday. A decrease in the oxygen content of the nutrient solution, together with a corresponding increase in respiration rate at this time (Hansen, 1977), could, unless the nutrient solution oxygen content was increased, limit growth, at least for part of the day, this suggests an increase in the oxygen content at this time should be considered.

\section{Conclusion}

The particular position of the internal layers within the NGS permitan improved oxigenation of plants roots, even when the length of the canal is four times longer than the traditional NFT system. Consequently it adapts much better to the agronomic conditions of different culture, where it does not have to be limited to the 5 or $7 \mathrm{~m}$ recommended for the NFT system

\section{Literature Cited}

Adams, P. 2002. Nutritional control in hydroponics, p. 211-262.. In: M. Savvas and H. Passam (eds.). Hydroponic production of vegetables and ornamentals. Embryo Publ., Athens.

Carrasco, G. 2004. Sistema NFT: requerimientos y usos, p. 541-554. In: M. Urrestarazu (ed.). Tratado de cultivo sin suelo. 3rd ed. Mundi-Prensa, Madrid.

Cooper, A. 1996. The ABC of NFT. 2nd ed. Casper Publ. Pty Ltd, Narrebeen, Australia.

Drew, M.C. 1983. Plant injury and adaptation to oxygen deficiency in the root environment: A review. Plant Soil 75:179-199.

Gilerød, H.R. and P. Adams. 1983. Diurnal variations in the oxygen conten and acid requirement of recirculanting nutrient solutions and in the uptake of water and potassium by cucumber and tomato plants. Scientia Hort. 21:311-321.

Gilerød, H.R. and R.J. Kempton. 1983. The oxygen content of flowing nutrient solutions used for cucumber and tomato culture. Scientia Hort. 20:23-33.

Hansen, G.K. 1977. Adaption to photosynthesis and diurnal oscillation of rootrespiration rates for Lolium multiflorum. Physiol. Plant. 39:275-279.

Jackson, M.B. 1980. Aeration in the nutrient film technique of glasshouse crop production and the importance of oxygen, ethylene and carbon dioxide. Acta Hort. 98:61-78.

Morard, P., L. Lacoste, and J. Silvestre. 2000. Effect of oxygen deficiency on uptake of water and mineral nutrients by tomato plants in soilless culture. J. Plant Nutr. 23(8):1063-1078.

Statistical Graphics Crop., 1999. STATGRAPHICS Plus for Windows 4.1. Statistical Graphics Crop., Rockville, Md.

Sonneveld, C. and N. Straver. 1994. Nutrient solutions for vegetables and flower grow in water o substrates. 10 th ed. Proefstation voor tuinbouw onder glas te Naaldiwjk. no. 8.

Zeroni, M., J. Gale, and J. Ben-Asher. 1983. Root Aeration in a deep hydroponic system and its effect on growth and yield of tomato. Scientia Hort. 19:213-220. 